Article

\title{
Association between New Urbanization and Sustainable Transportation: A Symmetrical Coupling Perspective
}

\author{
Fei Ma ${ }^{1}$, Yanru Guo ${ }^{1, *}$, Kum Fai Yuen ${ }^{2} \mathbb{D}$, Suhan Woo ${ }^{2}$ and Wenjing Shi ${ }^{1}$ \\ 1 School of Economics and Management, Chang'an University, Xi'an 710064, China; mafeixa@163.com (F.M.); \\ 2018123032@chd.edu.cn (W.S.) \\ 2 Department of International Logistics, Chung-Ang University, Seoul 08563, Korea; yuenkf@cau.ac.kr (K.F.Y.); \\ 2018123034@chd.edu.cn (S.W.) \\ * Correspondence: 2018123056@chd.edu.cn; Tel.: +86-029-82338715
}

Received: 3 January 2019; Accepted: 29 January 2019; Published: 9 February 2019

\begin{abstract}
New urbanization (NU) and sustainable transportation (ST) are two important issues in urbanization, and their symmetrical coupling is an important factor for measuring the development of the urbanization process. To comprehensively explore the symmetrical coupling level of NU and ST in the urbanization process, this study proposed a coupling coordination degree (CCD) model and calculated the CCD values of China's nine metropolises using panel data from 2007 to 2016. The results showed that: (1) From the perspective of each city's development, the CCD values for Beijing, Tianjin and Chongqing showed a downward trend, and those for Shanghai, Guangzhou, Chengdu and Wuhan exhibited a rising trend, while the CCD values for Zhengzhou and Xi'an fell initially and then rose gradually; (2) Based on the regions of the nine cities, the CCD values of the eastern cities and the central cities all demonstrated a growth trend, while those of the western cities were consistently lower than the central and eastern cities; however, the western cities experienced the highest growth rate. (3) Predictive results showed that the CCD levels of new urbanization and sustainable transportation in the eastern, central and western cities are projected to remain unchanged. Finally, it is expected that regionally balanced development will be realized in 2025. From the symmetrical coupling perspective, this study measured and predicted the coupling coordination level of NU and ST of nine metropolises undergoing the urbanization process, which provides a theoretical basis for effective decision-making for comprehensive and sustainable development of China's urbanization.
\end{abstract}

Keywords: new urbanization; entropy method; coupling coordination; sustainable transportation

\section{Introduction}

New urbanization (NU) and sustainable transportation (ST) are two important issues in the urbanization process, and the symmetrical coupling level between them is an important indicator of urbanization development [1]. NU differs from traditional urbanization in its emphasis on the intensity of the urbanization process, with wider meanings associated with urban-rural integration and sustainability [2]. ST is a mode of sustainable development which meets increasing transport demands in a way that promotes social equity, environmental friendliness and resource conservation, without damaging the natural environment [3]. The relationship between NU and ST is symmetrical and coupled. On the one hand, NU and ST are two relatively independent aspects of the process of urbanization. On the other hand, they are related through certain coupling and coordination aspects. Urban transportation is of a great significance for guiding urban spatial layout and supporting 
industrial layout, which are also indispensable factors in urbanization [4,5]. At the same time, the realization of NU is inseparable from the support of ST. In fact, transit-oriented development (TOD) is a reflection of the idea of symmetrical and coupled development in urbanization and urban transportation, and emphasizes a design approach that maximizes the use of public transportation when planning a residential or commercial area. Therefore, to promote sustainable urban construction and urban economic development, special attention needs to be paid to the two important aspects of NU and ST. Only when these two systems are in a coordinated and balanced stage of development, can corresponding positive externalities be produced to promote the process of urban construction; such as, the reduction of environmental pollution and the improvement of resource utilization [6]. If the $\mathrm{NU}$ is not aligned with the speed of development of ST, it will inevitably lead to management confusion and a large amount of resource wastage $[7,8]$. The existing literature suggests that a holistic view of the concepts of urbanization and transportation development is lacking. Without the proper coordination of ST and NU, outcomes will be inefficient. Therefore, to break this restrictive situation and achieve a virtuous circle of mutual promotion, it is imperative that the symmetrical coupling mechanism between NU and ST be clarified to finally obtain coordinated development of the two systems.

In recent years, with China's economy shifting from a high-speed growth stage to today's high-quality development stage, many cities, especially metropolises, have comprehensively promoted new urbanization [9]. The urbanization rate has increased from $26.21 \%$ in 1989 to $58.52 \%$ in 2017, with an average annual growth rate of $1.15 \%$ [10]. However, this rapid urbanization process has produced a series of problems, including environmental pollution, unreasonable land use, and a lack of transportation facilities, which are seriously hindering the development of urbanization [11,12]. According to data from the Ministry of Transport of China, national highway traffic congestion in 2015 totaled 0.39, of which the top five provinces in terms of congestion were Shanghai, Beijing, Guangdong, Zhejiang, and Shandong. In 2015, 78.4\% of China's urban ambient air quality exceeded the standard. Rapid urbanization requires sound public transport services and supporting infrastructure. Improved transportation infrastructure and reasonable transportation energy consumption will, in turn, have a positive effect on economic growth $[8,13]$. The unreasonable allocation of traffic resources and the imperfect public transport services will lead to transport deprivation (i.e., the travel of low-income groups is inhibited), further influencing the development of urbanization [13]. Therefore, it is necessary to evaluate the symmetrical coupling level between urbanization development and sustainable transportation in the metropolises of China, and further to predict future development trends, so as to provide a theoretical basis for the government agency to formulate a scientific and comprehensive urban development plan.

To date, many scholars have studied the relationship between urbanization and transport infrastructure, land use and transport behavior, but few have researched the coordinated development of NU and ST. Existing studies can be grouped into three categories: (1) Research on the supporting role of transportation infrastructure in urban development. For example, Gössling et al. used high-resolution digital satellite imagery combined with the geographic information system to calculate space allocations and evaluate the spatial distribution of urban transportation infrastructure. They emphasized that different transportation space allocations should be applied for different transportation modes [14]. Maparu et al. highlighted a long-term relationship between transportation infrastructure and economic development and urbanization, with this causal relationship extending from economic development to transportation infrastructure [15]; (2) Research on the relationship between urban land use patterns and the main traffic tools chosen by urban residents. For instance, Branea et al. proposed an analytical framework containing 15 standards to identify and quantify the key aspects of the main traffic patterns. The framework included hard quantitative data such as digital simulation, and mobility pattern analysis, and soft data such as quality assessments, and perceived demand and satisfaction. Their study highlighted that the quality of traffic infrastructure and the most effective means of transportation used by each particular city type may make urban development more sustainable [16]. Kwan et al. pointed out that travel duration, distance and purpose are important 
factors that affect residents' willingness to transfer to rail transit on weekdays [17]; (3) Research on the changes in urban morphology affecting travel behavior and, further, changing the choice of travel modes. For example, Loo et al. posited that urban expansion impacts sustainable transportation development, especially in Asian cities that have lower car ownership and more compact urban development. In these cities, changes in urban form impact travel behavior, and more people choose to avoid crowded urban centers [18]. Rukmanal et al. analyzed rapid urbanization demand for sustainable transportation policies in Jakarta, Indonesia, highlighting the finding that rapid urbanization led to an increase in urban vehicles. This in turn caused traffic congestion in Jakarta [19]. Therefore, the study proposed that Jakarta should vigorously promote public travel and encourage residents to ride bicycles or walk to alleviate traffic congestion during rapid urbanization. Ahmad et al. surveyed nationally representative households from the 98 largest cities in India and applied multivariate analyses to estimate the number and mode of public and private transportation (represented by out-of-pocket travel expenses). The survey showed that the densification of cities in India reduced the volume of traffic and increased the possibility of using public transport. Consequently, public transport development could improve the sustainability and inclusiveness of urban traffic [20].

In summary, the above literature indicates that there is a symmetrical coupling relationship between urbanization and transportation development in the development process, and that they interact and influence each other. Symmetrical coupling refers to the measure of mutual dependence for two or more entities in a common system, that is, there is a relationship of mutual interaction between the symmetrical entities [21,22]. At present, many scholars have applied symmetric coupling in related research, including the symmetrical coupling relationship between urbanization and ecological environment [23-25], as well as the interaction between economy, society and tourism [26-28]. Such studies provide a scientific reference for the study reported in this paper. However, few studies have analyzed the development of NU and ST from the perspective of symmetrical coupling, and quantitatively expressed the degree of coupling and coordination between the two systems as well as the consequences of their coordinated development [29].

At present, the uncoordinated development of urbanization and transportation systems in China is very prominent, especially in large cities. It is necessary to explore the mechanism of symmetrical and coordinated development between new urbanization and sustainable transportation theoretically. This study aimed to explore the symmetrical coupling degree of NU and ST in big cities, and uses China's nine metropolises (Beijing, Tianjin, Shanghai, Guangzhou, Chongqing, Chengdu, Wuhan, Zhengzhou and Xi'an) as research objects. Firstly, after referring extensively to the existing literature on evaluation indicators of urbanization and transportation system, this study constructed an evaluation index system for NU and ST. Thereafter, for measurement and analysis purposes, a coupling coordination degree (CCD) model was established to calculate the degree of symmetrical coupling between NU and ST, and the calculation results were analyzed with ArcGIS in different years. Next, combined with China's future urbanization development plan [30], a grey time series prediction method, namely the GM $(1,1)$ model, was used to predict the CCD values of the nine metropolises during the period 2019-2025. Finally, based on the results, we put forward optimization strategies for the future development of NU and ST in China, and provide suggestions for promoting comprehensive and sustainable urban development. The research framework of this study is shown in Figure 1.

The rest of the paper is structured as follows. Section 2 describes construction of the index systems, introduces the research model and method and calculates the coupling coordination degree (CCD) using the collected data. Section 3 discusses and analyzes the calculation results. The last section of the paper presents the conclusions and recommendations of this study. 


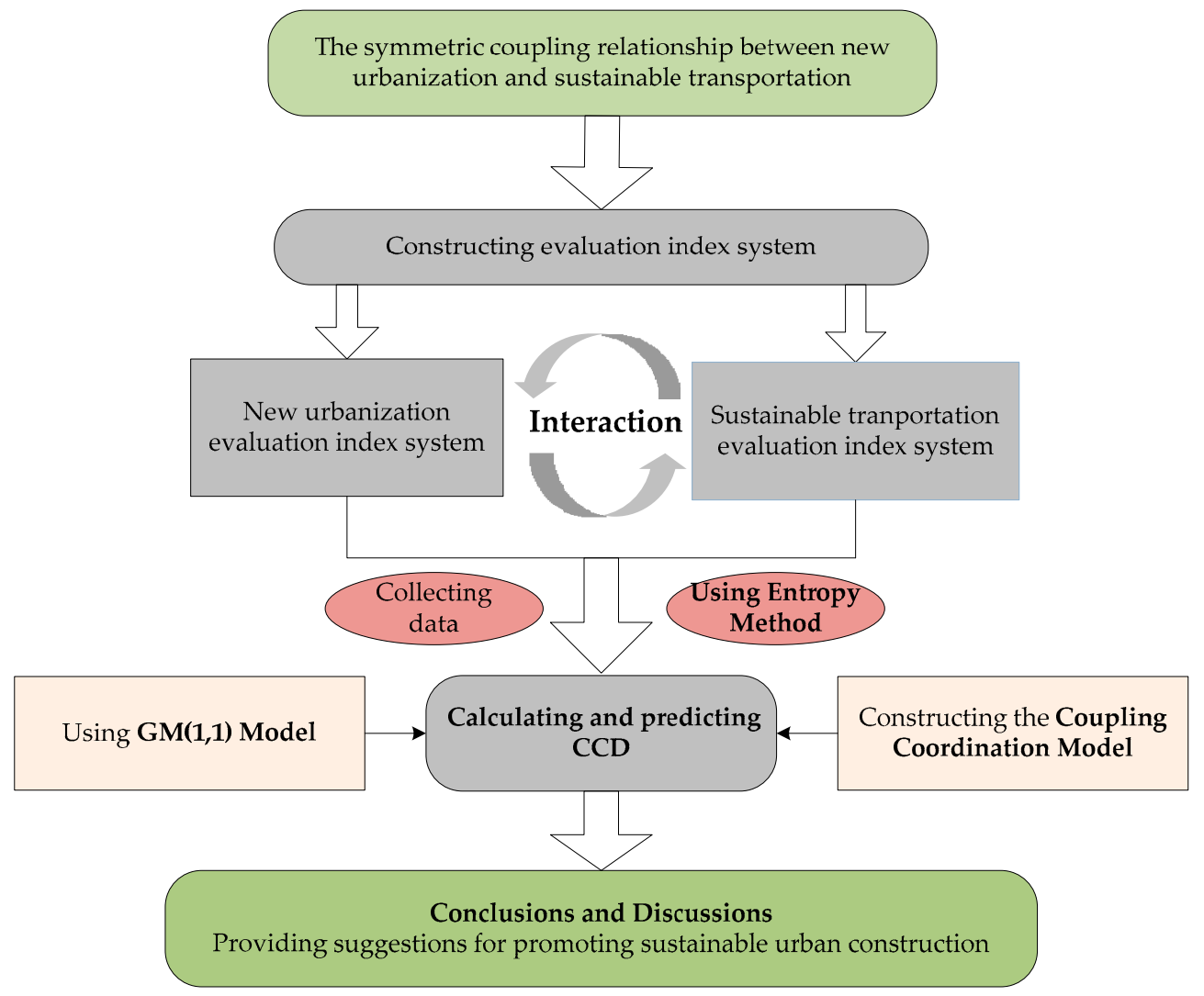

Figure 1. The research framework.

\section{Model and Data Sources}

\subsection{Construction of the Evaluation Index System}

The existing literature shows that there are many measures and index systems for assessing the level of development of traditional urbanization [31,32] and transportation [33,34]. Based on the relationship between urbanization and urban transportation (see Figure 2), this study synthesized the existing literature and identified the most cited and most convenient indicators for urban development and urban transportation. Then we established a scientific and objective evaluation index system in accordance with the research purpose.

The core concept of NU is green, open, shared and coordinated urbanization [2]. Current indicators for measuring new urbanization include: population urbanization [35], economic urbanization [36], social urbanization [37], urban-rural development coordination [38], and environmental-friendliness [38]. Among these, population urbanization reflects the process of population centralization to cities and towns, mainly expressed as the proportion of urban population to total population and proportion of secondary and tertiary industrial occupation $[33,35]$. Economic urbanization refers to the process and mechanism of rural economic transformation to an urban economy, which is the driving force of urbanization $[36,39]$. It is measured by the per capita GDP and the proportion of secondary and tertiary industrial output. Social urbanization reflects the level of construction of public service facilities during the process of urbanization, and is mainly shown in per capita urban road area, ownership of public buses per ten thousand people, the ratio of participation in pension insurance and the number of public libraries [37]. Coordinated development of urban and rural areas is an important step towards narrowing the gap between urban and rural areas, which is mainly reflected in the urban-rural per capita disposable income ratio, urban-rural per capita consumption expenditure ratio and urban-rural per capita education investment ratio [40]. Environmental friendliness is the embodiment of new urbanization's intensive 
environmental protection emphasis, mainly represented by the green coverage rate of the built-up district, per capita green park area, and the comprehensive utilization rate of industrial waste, energy saving and environmental protection investment ratio [40].

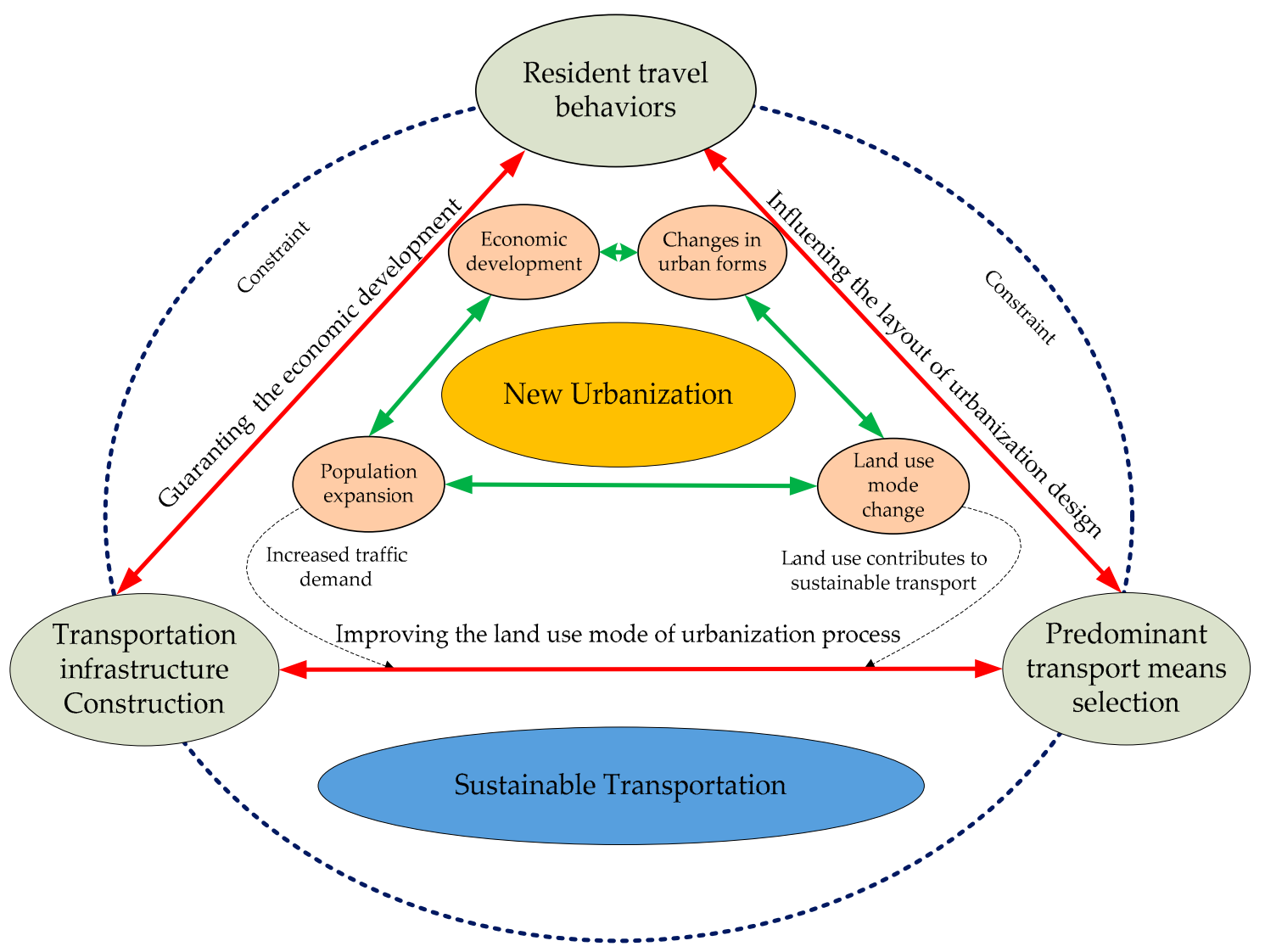

Figure 2. The relationship between urbanization and urban transportation.

The goal of ST is to achieve coordinated transportation development across society, the economy and the environment. ST emphasizes the protection of the environment and the rational use of resources while meeting social needs [40]. Therefore, an evaluation index system can be established from the perspective of social, economic and environmental coordination. Evaluation index system measures include the adaptability of urban traffic function [41], urban residents' travel satisfaction [42], the degree of coordination of urban traffic development [43], and the degree of influence of urban environment resources [44].

Based on the above analysis, we established an evaluation index system. The NU index system included five secondary indicators (population urbanization, economic urbanization, social urbanization, urban-rural development coordination, and environmental-friendliness) and 18 third-level indicators. The ST index system contained four secondary indicators (adaptability of urban traffic functions, urban resident travel satisfaction, coordination degree of urban traffic development, and the degree of influence of urban environmental resources) and 22 third-level indicators. Tables 1 and 2 show the evaluation index systems. 
Table 1. Evaluation index system for new urbanization.

\begin{tabular}{|c|c|c|c|c|c|c|}
\hline Target Layer & Factor Layer & Index Layer & Indicator Name & Index Effect & Sources & Index Weight \\
\hline \multirow{18}{*}{$\begin{array}{l}\text { New } \\
\text { urbanization }\end{array}$} & \multirow{2}{*}{$\begin{array}{l}\text { Population } \\
\text { urbanization }\end{array}$} & The proportion of urban population to total population (\%) & $\mathrm{X} 1$ & + & {$[31,32]$} & 0.0656 \\
\hline & & Proportion of secondary and tertiary industrial occupation (\%) & $\mathrm{X} 2$ & + & {$[33,35]$} & 0.0466 \\
\hline & \multirow{2}{*}{$\begin{array}{l}\text { Economic } \\
\text { urbanization }\end{array}$} & Per capita GDP (yuan) & $\mathrm{X} 3$ & + & [36] & 0.0615 \\
\hline & & Proportion of secondary and tertiary industrial output $(\%)$ & $\mathrm{X} 4$ & + & {$[37,39]$} & 0.0612 \\
\hline & \multirow{7}{*}{ Social urbanization } & Per capita urban road area (square meter/person) & X5 & + & [38] & 0.0572 \\
\hline & & Ownership of public buses per ten thousand people (standard bus) & $\mathrm{X} 6$ & + & {$[33,35,36]$} & 0.0567 \\
\hline & & Number of beds per 10,000 people in health care institutions (sheets) & $\mathrm{X} 7$ & + & [2] & 0.0503 \\
\hline & & A public toilet for every 10,000 people (seat) & $\mathrm{X} 8$ & + & {$[2,37]$} & 0.0605 \\
\hline & & Ratio of participation in pension insurance & X9 & + & [31] & 0.0458 \\
\hline & & Per capita investment in education (yuan) & $\mathrm{X} 10$ & + & {$[32,36]$} & 0.0382 \\
\hline & & Public library collections (ten thousand copies) & X11 & + & [32-34] & 0.0792 \\
\hline & \multirow{3}{*}{$\begin{array}{l}\text { Urban-rural } \\
\text { development } \\
\text { coordination }\end{array}$} & Urban-rural per capita disposable income ratio & $\mathrm{X} 12$ & - & [36] & 0.0618 \\
\hline & & Urban-rural per capita consumption expenditure ratio & $\mathrm{X} 13$ & - & [2] & 0.0489 \\
\hline & & Urban-rural per capita education investment ratio & $\mathrm{X} 14$ & - & [33] & 0.0501 \\
\hline & \multirow{4}{*}{ Environmentally-friendly } & Green coverage rate of the built-up district (\%) & $\mathrm{X} 15$ & + & {$[37,38]$} & 0.0423 \\
\hline & & Per capita park green area $(\%)$ & $\mathrm{X} 16$ & + & [38] & 0.0568 \\
\hline & & The comprehensive utilization rate of industrial waste (\%) & X17 & + & {$[32,39]$} & 0.0545 \\
\hline & & Energy saving and environmental protection investment ratio (\%) & $\mathrm{X} 18$ & + & {$[38]$} & 0.0630 \\
\hline
\end{tabular}


Table 2. Evaluation index system of urban sustainable transportation.

\begin{tabular}{|c|c|c|c|c|c|c|}
\hline Target Layer & Factor Layer & Index Layer & Indicator Name & Index Effect & Sources & Index Weight \\
\hline \multirow{22}{*}{$\begin{array}{c}\text { Urban } \\
\text { sustainable } \\
\text { transportation }\end{array}$} & \multirow{8}{*}{$\begin{array}{l}\text { Adaptability of urban } \\
\text { traffic function }\end{array}$} & Urban road network density $\left(\mathrm{km} / \mathrm{km}^{2}\right)$ & $\mathrm{Y} 1$ & + & {$[41,44]$} & 0.0377 \\
\hline & & Per capita road area $(\mathrm{m} 2)$ & $\mathrm{Y} 2$ & + & {$[41,44]$} & 0.0459 \\
\hline & & Urban road network connectivity & $\mathrm{Y} 3$ & + & [42-44] & 0.0461 \\
\hline & & Traffic management informatization level (\%) & $\mathrm{Y} 4$ & + & {$[45,46]$} & 0.0523 \\
\hline & & Bus travel ratio $(\%)$ & Y5 & + & {$[41,43]$} & 0.0390 \\
\hline & & Load balance of urban road network & Y6 & + & [47] & 0.0543 \\
\hline & & Proportion of urban transportation professionals (\%) & Y7 & + & [45] & 0.0385 \\
\hline & & Traffic regulation support capacity $(\%)$ & Y8 & + & {$[41,44]$} & 0.0368 \\
\hline & \multirow{5}{*}{$\begin{array}{l}\text { Urban residents' } \\
\text { travel satisfaction }\end{array}$} & Ownership of public bus per 10,000 people (Standard bus) & Y9 & + & {$[42,46]$} & 0.0455 \\
\hline & & Coverage of bus stations (\%) & Y10 & + & {$[42,47]$} & 0.0593 \\
\hline & & $90 \%$ residents travel time consumption $(\mathrm{min})$ & $\mathrm{Y} 11$ & - & {$[41,42,44]$} & 0.0394 \\
\hline & & Average transfer coefficient & $\mathrm{Y} 12$ & - & {$[42,46,47]$} & 0.0401 \\
\hline & & Average speed of urban main lines $(\mathrm{km} / \mathrm{h})$ & $\mathrm{Y} 13$ & + & {$[41,45]$} & 0.0458 \\
\hline & \multirow{4}{*}{$\begin{array}{l}\text { Coordination degree } \\
\text { of urban traffic } \\
\text { development }\end{array}$} & Urban transportation investment coordination coefficient (\%) & Y14 & + & {$[43,45]$} & 0.0508 \\
\hline & & Urban transportation cost coordination coefficient & Y15 & + & {$[43,44]$} & 0.0482 \\
\hline & & Coordination coefficient of urban traffic safety $(\%)$ & Y16 & - & {$[46,47]$} & 0.0530 \\
\hline & & The balance of urban regional traffic development & Y17 & + & [45] & 0.0374 \\
\hline & \multirow{5}{*}{$\begin{array}{l}\text { Influence degree of } \\
\text { urban environment } \\
\text { resources }\end{array}$} & Ratio of traffic environmental protection investment to GDP (\%) & Y18 & + & {$[44,45]$} & 0.0482 \\
\hline & & Substitution rate for clean energy use (\%) & Y19 & + & {$[41,46]$} & 0.0506 \\
\hline & & Mean value of main traffic line noise (decibels- $\mathrm{dB}(\mathrm{A})$ ) & $\mathrm{Y} 20$ & - & {$[40,41,43]$} & 0.0548 \\
\hline & & Green coverage rate in urban area $(\%)$ & $\mathrm{Y} 21$ & + & [41] & 0.0339 \\
\hline & & Vehicle emission standard rate $(\%)$ & $\mathrm{Y} 22$ & + & {$[41,44]$} & 0.0425 \\
\hline
\end{tabular}




\subsection{Construction of the Coupling Coordination Degree (CCD) Model}

\subsubsection{Data Standardization and Weight Calculation}

Before calculating the CCD of NU and ST, the index weight should first be determined. This study used the entropy method to determine the index weight. The entropy method is an objective weighting method, which determines the index weight based on the magnitude of information provided by each index observation value $[24,48]$. The greater the amount of information, the smaller the entropy. That is, the more the index changes, the more it affects the structure of the system. Thus, it is suitable for the comprehensive evaluation of multiple indices. The selected indices of the NU and ST systems differ in their dimensions and directions. To further reduce the information overlap of index variables and biases caused by subjective factors in the weight calculation process, the following method was applied to determine the weight of the index. The detailed steps are as follows.

First, the data were standardized using the extreme value method to homogenize the heterogeneous index. The positive index was processed using Formula (1), and the negative index was processed using Formula (2). After processing using the extreme method, some data appeared as 0 and 1.

It was necessary to take the natural logarithm of the normalized data and the antilogarithm must be greater than 0 ; as such, the entropy method was no longer suitable. This study panned the standardized data by 2 units. Then, the entropy method was used to calculate the weight of each index in the two systems: new urbanization and sustainable transportation. The specific process for calculating the weight is shown in Figure 3. The calculation process was as follows:

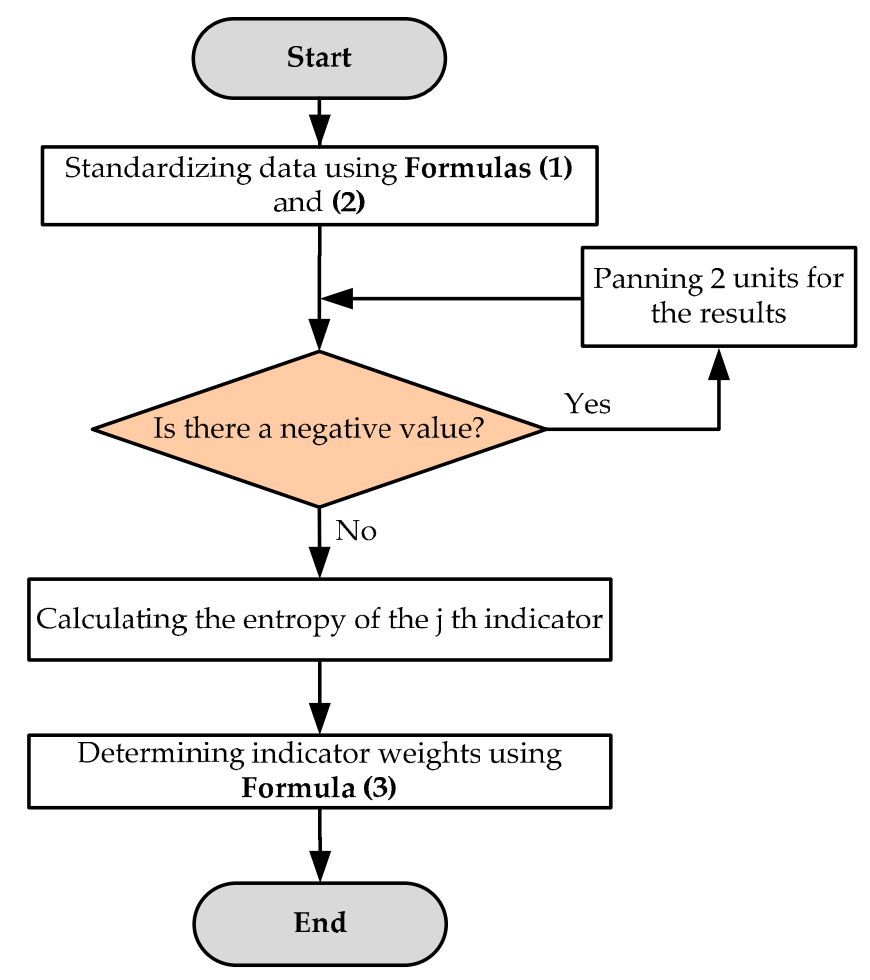

Figure 3. The flow chart of weight calculation.

(1) Data standardization processing:

$$
\begin{aligned}
X_{i j}^{\prime} & =\frac{X_{j}-X_{\text {min }}}{X_{\text {max }}-X_{\text {min }}}+2 \\
X_{i j}^{\prime} & =\frac{X_{\text {max }}-X_{j}}{X_{\text {max }}-X_{\text {min }}}+2
\end{aligned}
$$


where $X_{\max }$ is the maximum value of item $j$ index for the year $r ; X_{\min }$ is the minimum value of item $j$ index for the year $r ; X_{j}$ is the corresponding value of item $j$; and $X_{i j}^{\prime}$ is the normalized value of the original data.

(2) Calculating the entropy of each index. Assume there are m evaluation objects, $\mathrm{n}$ evaluation indicators, and the number of statistical years is $\mathrm{r}$. In this study, we set $m=9, r=$ 10. The normalized data matrix $X_{i j}^{\prime}=\left(x_{i j}^{\prime}\right)_{m * n}$. Then, the entropy of the $\mathrm{j}$-th index is $E_{j}=-k \sum_{r=1}^{10} \sum_{i=1}^{m} x_{i j}^{\prime \prime} \ln \left(x_{i j}^{\prime \prime}\right)$, where, $k=1 / \ln (m r), x_{r i j}^{\prime \prime}=\frac{x_{r i j}^{\prime}}{\sum_{r=1}^{10} \sum_{i=1}^{m} x_{r i j}^{\prime}}$.

(3) Calculating the index weights.

$$
w_{j}=\frac{d_{j}}{\sum_{j=1}^{n} d_{j}}
$$

where $d_{j}$ is the difference coefficient of the $j$-th index; $d_{j}=1-E_{j}$; and $w_{j}$ is the index weight.

(4) Calculating the comprehensive evaluation score of the NU and ST of each city.

$$
U_{n}=\sum_{j=1}^{n} w_{j} x_{i j}{ }^{\prime \prime}, U_{s}=\sum_{j=1}^{n} \sigma_{j} y_{i j}{ }^{\prime \prime}
$$

where $w_{j}$ and $\sigma_{j}$ are the corresponding index weights for the new urbanization and sustainable transportation subsystems. The variables $U n$ and $U_{s}$ represent the comprehensive NU and ST scores, respectively. When $U_{n}>U_{s}$, ST development lagged behind NU; when $U_{n}<U_{s}$, NU lagged behind ST. When $U_{n}=U_{s}, \mathrm{NU}$ and ST were in a state of coordinated development.

\subsubsection{Coupling Coordination Degree (CCD) Model}

The coupling degree describes the level of interaction among various elements in the system, which determines the trend from disorder to order [48]. Coordination refers to a benign interrelationship between two or more systems or system elements, which is a well-coordinated, harmonious, and virtuous circle between systems or within systems. If the coupling degree of subsystems is high and the subsystems cooperate with each other, the system will move from disorder to order and maintain its vigorous vitality. If the subsystems are not coordinated and cooperative, they will restrict each other, and the system will move from order to disorder, and may even stagnate or decline. Therefore, we believe that the coupling and coordination relationship between NU and ST can be explained as follows. To achieve the overall system objectives, the NU and ST need to have synergies, complementarities and other interrelationships. Subsequently, the level of coordination reflected by the interaction can be defined as the coupling coordination degree (CCD).

There is an interactive relationship between the two systems of NU and ST. The degree of symmetrical coupling measures the association between subsystems of NU and ST, meaning the extent to which acceleration of NU has concurrently promotes the development of ST and ST improves the realization of NU. It can reflect the degree of interaction among the systems [24,48]. To reflect the real development of the two systems scientifically, we chose a CCD model to measure them. The CCD model can be used not only to identify the interaction and coupling of the two systems, but also to reflect the relative differences in the degree of development of NU and ST.

Therefore, in this study the degree of interaction between the two subsystems was defined as the system coupling degree (COP). The COP does not clearly reflect the dynamic trends between the NU and ST systems. As such, the coupling coordination degree (CCD) was defined. The CCD captures 
whether each system has a good level of coordination and can reflect the interactional relationships between the systems [48]. The CCD model is given in the following formulas:

$$
\begin{gathered}
C O P=\left[U_{n} \cdot U_{s} /\left(U_{n}+U_{s}\right)^{2}\right]^{\frac{1}{2}} \\
T=\alpha U_{n}+\beta U_{s} \\
C C D=\sqrt{T \cdot C O P}
\end{gathered}
$$

where $T$ is the degree of development of new urbanization and sustainable transportation, which is the comprehensive development index of the two subsystems. COP is the degree of coupling, and $\alpha, \beta$ are the undetermined coefficients satisfying $\alpha+\beta=1$. This study assumed that new urbanization and sustainable transportation are equally important. As such, $\alpha=0.5, \beta=0.5$. Based on previous studies, this study provides evaluation criteria for coupling coordination and the development stage of new urbanization and sustainable transportation (see Table 3). The closer the coupling coordination degree is to 1 , the better the coupling coordination between the two systems. The closer the coupling coordination degree is to 0 , the worse the coupling coordination.

Table 3. Coupling coordination type and development stage.

\begin{tabular}{ccc}
\hline CCD & Coordination Type & Coordination Stage \\
\hline$(0.0,0.199]$ & Severe imbalance & \\
{$[0.2-0.299)$} & Moderate imbalance & Disorder stage \\
{$[0.3-0.399)$} & Mild disorder & \\
\hline$[0.4-0.499)$ & On the verge of imbalance & Transition stage \\
{$[0.5-0.599)$} & Reluctant coordination & \\
\hline$[0.6-0.699)$ & Primary coordination & \\
{$[0.7-0.799)$} & Intermediate coordination & Coordination stage \\
{$[0.8-0.899)$} & Good coordination & \\
{$[0.9-1.000)$} & Quality coordination & \\
\hline
\end{tabular}

\section{3. $G M(1,1)$ Model}

Grey System Theory (Grey Theory) was first proposed and studied by Deng [49] in the 1980s. The theory proposes that a system can be orderly and functional, even when some system features are unknown to the user and the data are complex. The grey system has incomplete information between the black system and the white system. The information is incomplete because the structure of the system is not fully known, and the mechanisms driving the interactions among the system's different elements are not completely clear [50,51]. The system consisting of NU and ST is influenced by many factors, such as economic level, living standard, population growth, etc. However, the influencing mechanism between each factor is not completely clear. That is, the system consisting of NU and $\mathrm{ST}$ is an incomplete system which contains both unknown and uncertain information, and mixed information, and is thus a typical grey system. Therefore, a grey time series prediction method GM(1, 1) model was used to predict the coupling coordination degree of the NU and ST of the nine national metropolises in this study so that we could correctly grasp the development trend of CCD between $\mathrm{NU}$ and ST, and make timely policy adjustments to promote the construction of sustainable cities.

(1) Define the time series of CCD between new urbanization and sustainable transportation in different regions: $D^{(0)}=\left(D^{(0)}(1), D^{(0)}(2), \cdots, D^{(0)}(n)\right)$, where, $D^{(0)}(k)>0, k=1,2,3, \cdots, n$. Then, calculate the level ratio of the original sequence:

$$
\lambda(k)=\frac{D^{(0)}(k-1)}{D^{(0)}(k)}
$$


where $k=2,3, \cdots, n$. If all the ratios fall between the intervals $\left(e^{\frac{-2}{n+1}}, e^{\frac{2}{n+1}}\right)$, the series $D^{(0)}$ can be predicted using the $\operatorname{GM}(1,1)$ model. Otherwise, the original series needs to be appropriately transformed as follows:

(2) If $D^{(0)}$ satisfies the above requirements, the original time series $D^{(0)}(k)$ is accumulated. The formula is as follows:

$$
D^{(1)}(k)=\sum_{i=1}^{k} D^{(0)}(i)
$$

where $D^{(1)}=\left(D^{(1)}(1), D^{(1)}(2), \cdots, D^{(1)}(n)\right)$ is the 1-AGO sequence of $D^{(0)}(k), k=1,2,3, \cdots, n$;

(3) Establish a GM(1,1) model

$$
D^{(0)}(k)+a Z^{(1)}(k)=b
$$

where $Z^{(1)}(k)=\frac{1}{2}\left(D^{(1)}(k)+D^{(1)}(k-1)\right), k=2,3, \cdots, n$.;

(4) Estimate the value of $a, b$ using the least squares method. The calculation formula is as follows:

$$
u=\left[\begin{array}{l}
a \\
b
\end{array}\right]=\left(B^{T} B\right)^{-1} B^{T} Y
$$

where $Y=\left[\begin{array}{c}D^{(0)}(2) \\ D^{(0)}(3) \\ \vdots \\ D^{(0)}(n)\end{array}\right], B=\left[\begin{array}{cc}-Z^{(1)}(2) & 1 \\ -Z^{(1)}(3) & 1 \\ \vdots & \vdots \\ -Z^{(1)}(n) & 1\end{array}\right]$

(5) The prediction model is as follows:

$$
\stackrel{\wedge}{D}^{(1)}(k+1)=\left(D^{(0)}(1)-\frac{b}{a}\right) e^{-a k}+\frac{b}{a}
$$

(6) The model is then tested.

Residual test:

$$
\varepsilon(k)=\left|\frac{\stackrel{\wedge}{D}^{(1)}(k)-D^{(0)}(k)}{D^{(0)}(k)}\right|
$$

Level ratio deviation value test:

$$
\rho(k)=\left|1-\frac{1-0.5 \cdot a}{1+0.5 \cdot a} \lambda(k)\right|
$$

In Formulas (12) and (13), $k=1,2,3, \cdots, n$.

\subsection{Data Sources}

In this study, nine national metropolises in China were the research areas. They included Beijing, Tianjin, Shanghai, Guangzhou, Chongqing, Chengdu, Zhengzhou, Wuhan, and Xi'an (see Figure 4). The study period was 2007-2016. The data in the new urbanization index system were mainly collected from the 2008-2017 Statistical Yearbooks for each metropolis. The data related to the sustainable transportation index system were mainly collected from the urban traffic yearbooks for the different cities. 


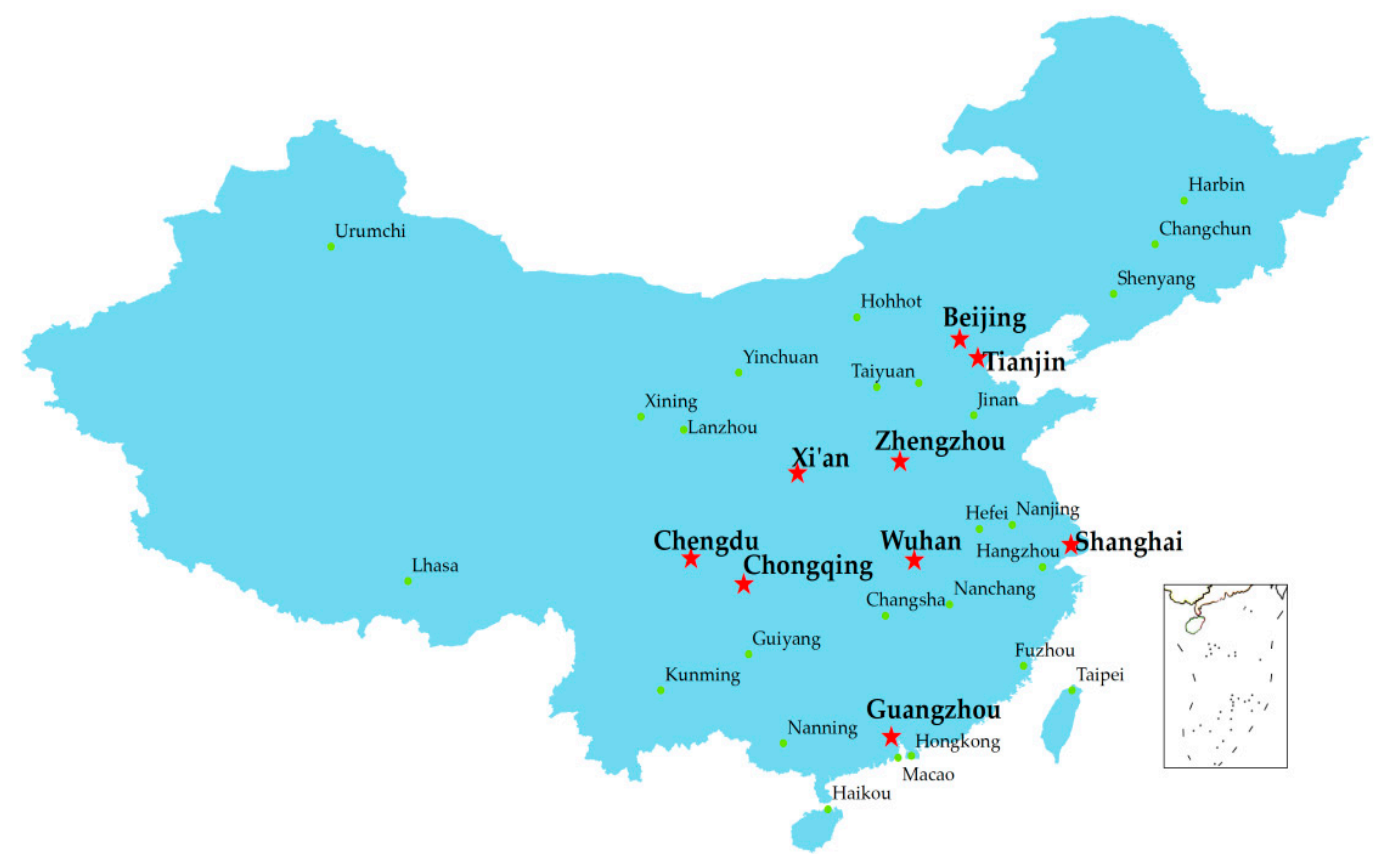

Figure 4. Study area (red sections represent the nine metropolises).

\section{Empirical Research}

\subsection{Comprehensive Score Analysis of New Urbanization and Sustainable Transportation}

Using the original data for 2007-2016 from the nine national metropolises, Formulas (1)-(3) were used to calculate the corresponding index weights (the results are shown in Tables 1 and 2), and Formula (4) was used to obtain the comprehensive score for new urbanization and sustainable transportation for each city (see Tables 4 and 5, and Figure 5). Beijing's comprehensive new urbanization score fluctuated over time, dropping between 2012 and 2013 from 0.75 to 0.63 . However, the value remained higher than the other eight cities in the same year. This indicates that Beijing's new urbanization growth rate was the highest among the cities. In contrast, the comprehensive new urbanization score for Shanghai declined over time, from a maximum of 0.69 to 0.45 . This is because of the large capital investments required to promote new urbanization. Government revenue is insufficient to support this need, and a shortage of construction land in the city also restricted new urbanization.

Table 4. Comprehensive new urbanization scores in nine metropolises from 2007 to 2016.

\begin{tabular}{cccccccccc}
\hline \multirow{2}{*}{ Year } & \multicolumn{7}{c}{ City } \\
\cline { 2 - 9 } & Beijing & Tianjin & Shanghai & Guangzhou & Chongqing & Chengdu & Wuhan & Zhengzhou & Xi'an \\
\hline 2007 & 0.71 & 0.57 & 0.68 & 0.62 & 0.21 & 0.39 & 0.51 & 0.33 \\
2008 & 0.69 & 0.58 & 0.69 & 0.61 & 0.18 & 0.42 & 0.48 & 0.33 & 0.40 \\
2009 & 0.72 & 0.58 & 0.69 & 0.69 & 0.25 & 0.38 & 0.57 & 0.34 & 0.38 \\
2010 & 0.73 & 0.59 & 0.63 & 0.60 & 0.24 & 0.45 & 0.58 & 0.38 & 0.37 \\
2011 & 0.73 & 0.59 & 0.56 & 0.62 & 0.25 & 0.39 & 0.52 & 0.37 & 0.33 \\
2012 & 0.75 & 0.60 & 0.55 & 0.64 & 0.26 & 0.39 & 0.54 & 0.35 & 0.35 \\
2013 & 0.63 & 0.56 & 0.45 & 0.53 & 0.24 & 0.36 & 0.47 & 0.28 & 0.36 \\
2014 & 0.72 & 0.58 & 0.57 & 0.59 & 0.24 & 0.37 & 0.50 & 0.32 & 0.31 \\
2015 & 0.71 & 0.56 & 0.56 & 0.58 & 0.32 & 0.41 & 0.50 & 0.35 \\
2016 & 0.72 & 0.58 & 0.59 & 0.60 & 0.30 & 0.41 & 0.53 & 0.38 \\
\hline
\end{tabular}

The new urbanization scores for Chongqing, Chengdu, Zhengzhou, and Wuhan were all small; however, they showed a positive increasing trend over time. This is mainly because these cities are rich in resources and have vast territories. This maximized the advantages of starting later and the 
rapid promotion of new urbanization. In addition, the new urbanization scores in the eastern cities (Beijing, Tianjin, Shanghai, and Guangzhou) decreased year by year, at a rate of 3.85\%. In contrast, the NU scores for the central cities (Zhengzhou, Wuhan) and the western cities (Chongqing, Chengdu and $\mathrm{Xi}^{\prime}$ an) increased, with some fluctuation. The NU growth rate for the central cities was $8.26 \%$, and the NU growth rate for the western cities was $6.32 \%$. This increase was mainly due to the support of national policies over the previous years. The central and western cities were able to maximize their respective advantages to achieve rapid development.

Table 5. Comprehensive sustainable transportation scores for nine metropolises from 2007 to 2016.

\begin{tabular}{cccccccccc}
\hline \multirow{2}{*}{ Year } & \multicolumn{7}{c}{ City } \\
\cline { 2 - 10 } & Beijing & Tianjin & Shanghai & Guangzhou & Chongqing & Chengdu & Wuhan & Zhengzhou & Xi'an \\
\hline 2007 & 0.59 & 0.64 & 0.58 & 0.55 & 0.36 & 0.41 & 0.47 & 0.39 & 0.42 \\
2008 & 0.62 & 0.67 & 0.53 & 0.58 & 0.30 & 0.39 & 0.48 & 0.43 & 0.43 \\
2009 & 0.67 & 0.65 & 0.53 & 0.58 & 0.34 & 0.34 & 0.46 & 0.43 & 0.44 \\
2010 & 0.59 & 0.69 & 0.51 & 0.58 & 0.32 & 0.34 & 0.49 & 0.45 & 0.45 \\
2011 & 0.63 & 0.67 & 0.54 & 0.57 & 0.30 & 0.34 & 0.48 & 0.49 & 0.43 \\
2012 & 0.63 & 0.68 & 0.47 & 0.53 & 0.34 & 0.28 & 0.46 & 0.39 & 0.41 \\
2013 & 0.67 & 0.70 & 0.58 & 0.50 & 0.32 & 0.26 & 0.45 & 0.36 & 0.40 \\
2014 & 0.67 & 0.68 & 0.59 & 0.50 & 0.32 & 0.31 & 0.44 & 0.38 & 0.45 \\
2015 & 0.66 & 0.68 & 0.55 & 0.51 & 0.32 & 0.33 & 0.35 & 0.41 & 0.49 \\
2016 & 0.67 & 0.67 & 0.63 & 0.56 & 0.36 & 0.34 & 0.43 & 0.42 & 0.50 \\
\hline
\end{tabular}

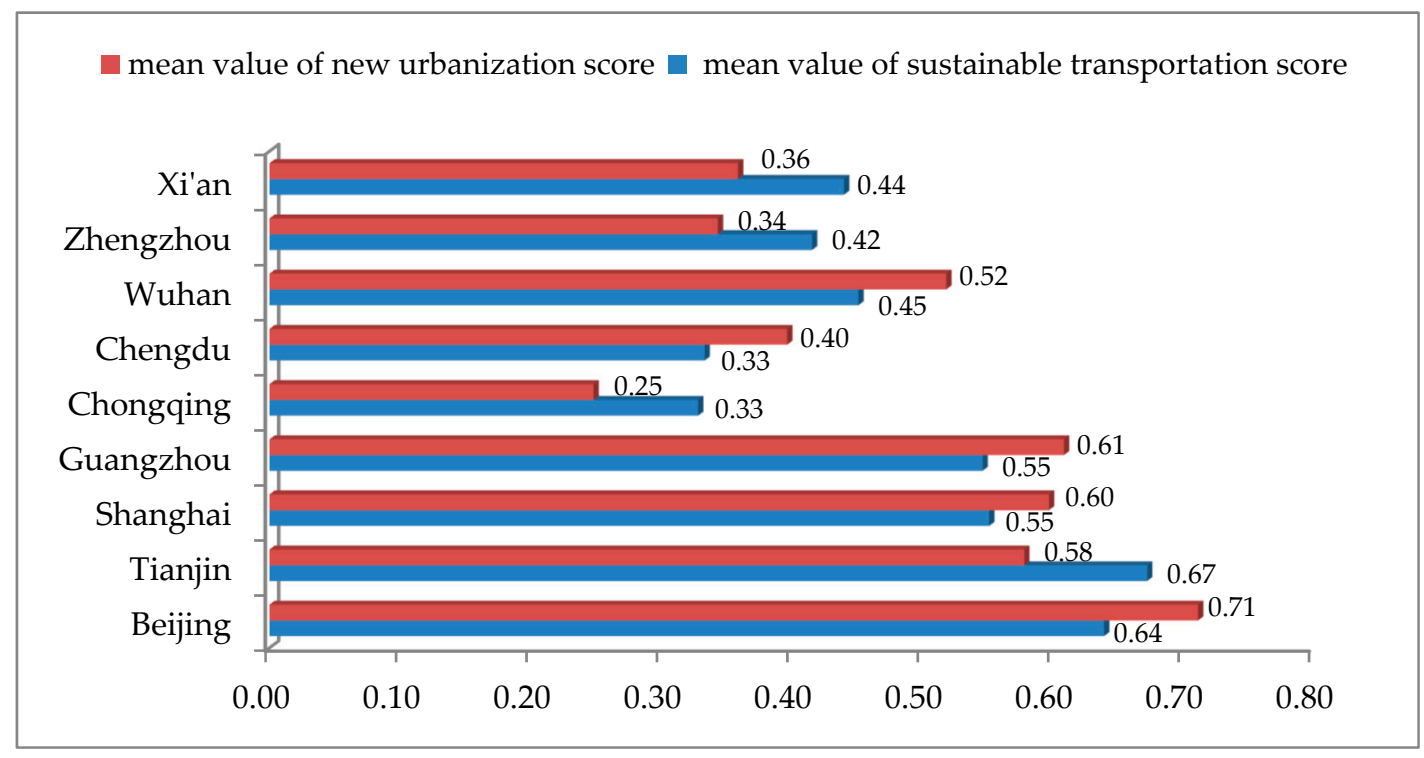

Figure 5. The mean value of new urbanization (NU) and sustainable transportation (ST) scores for nine metropolises from 2007-2016.

With respect to the comprehensive sustainable transportation score, Figure 5 shows that the average scores of new urbanization in Beijing, Shanghai, Guangzhou, Chengdu, and Wuhan were greater than the average sustainable transportation scores. That is, sustainable transportation development lagged behind new urbanization. In contrast, for Tianjin, Chongqing, Zhengzhou and $\mathrm{Xi}^{\prime}$ an the development of new urbanization lagged behind sustainable transportation.

\subsection{Analysis of Coupling Coordination Degree}

Data in Tables 4 and 5 and Formulas (5)-(7) were used to calculate the COP, T and CCD. Table 6 shows the resulting calculated CCD values and results of the analysis are shown in Figures 6 and 7. 


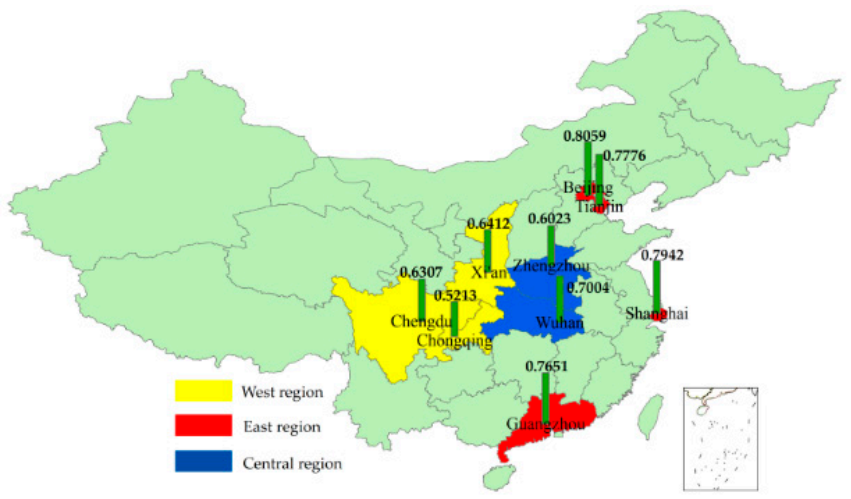

(a) 2007

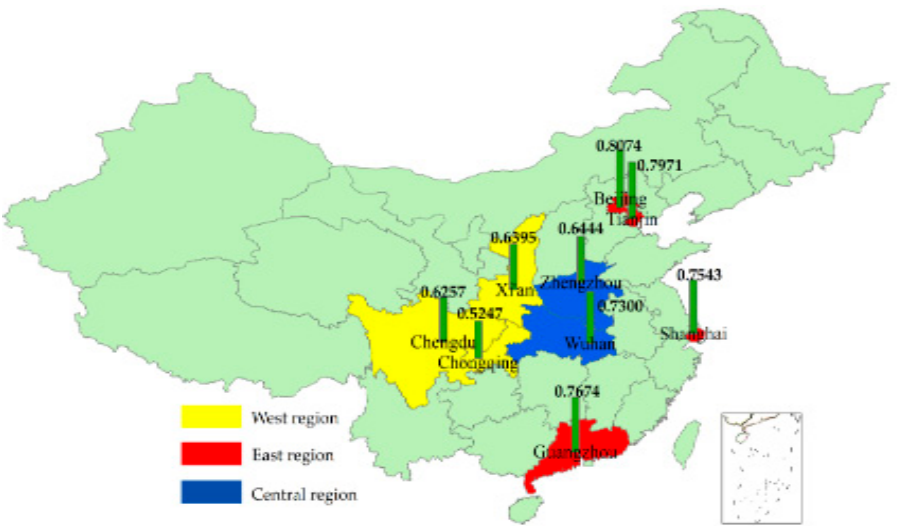

(b) 2010

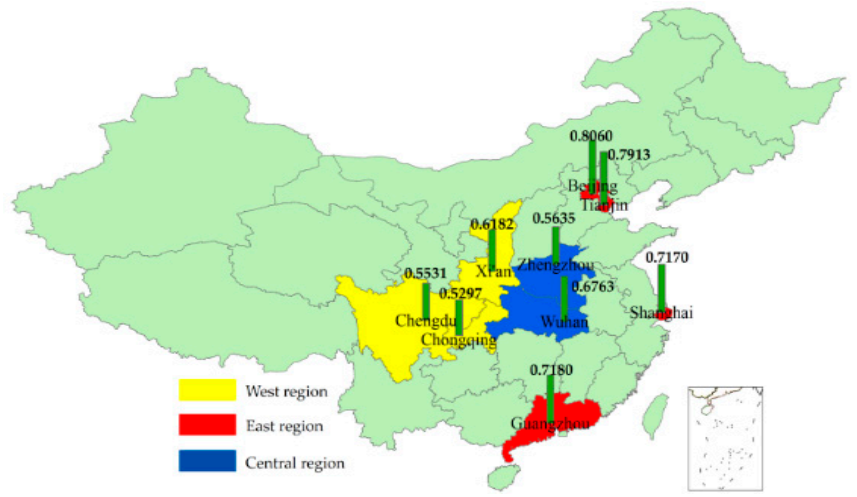

(c) 2013

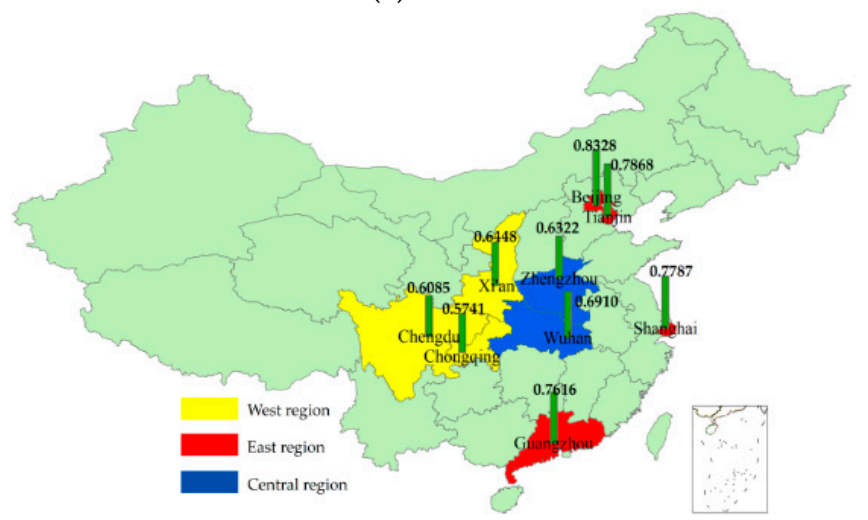

(d) 2016

Figure 6. Coupling coordination degree of each city in (a) 2007, (b) 2010, (c) 2013, and (d) 2016. 
Table 6, and Figures 6 and 7, show that the CCD values between NU and ST of three cities (Beijing, Tianjin and Chongqing) exhibited a fluctuating downward trend from 2007 to 2016. The CCD values for Beijing decreased by $2.4 \%$; however, the $C C D$ values between the two systems consistently remained between 0.80 and 0.84 , which is in the good coordination stage. The CCD values for Tianjin fell $1.3 \%$ but remained in the intermediate coordination stage. The CCD values for Chongqing decreased by $8.7 \%$, which was in the basic coordination stage before 2014 and then fell into the dysfunctional stage in 2014, demonstrating that new urbanization lagged behind sustainable transportation development.

The CCD values for Shanghai, Guangzhou, Chengdu, and Wuhan all rose at a volatile rate. Shanghai showed a straight upward trend from 2011 to 2016 with a growth rate of $10.13 \%$, representing an intermediate stage of coordinated development. The CCD value growth rate for Guangzhou was $1.3 \%$, also in the intermediate coordination stage. The CCD values for Chengdu grew by $3.17 \%$, developing from a grudging coordination stage to an initial coordination stage. The CCD values for Wuhan grew by $1.5 \%$, developing from the primary coordination stage to the intermediate coordination stage.

The CCD for Zhengzhou was in a consistent state of decline before 2010. However, after 2010, it began to significantly recover and CCD values changed from 0.56 to 0.64 , reflecting a change in the two systems from the reluctant coordination stage to the primary coordination stage. In $\mathrm{Xi}^{\prime}$ an, the CCD values first declined and then rebounded, but remained in the primary coordination stage. Based on the location of the metropolises, the sustainable transportation comprehensive score in the eastern cities increased over time, at a growth rate of $6.33 \%$ which was consistently higher than the central and western cities. The central cities experienced a downward fluctuating trend, but were consistently higher than the western cities. The CCD values of the western cities experienced slow growth, at a rate of $0.30 \%$. The consistently higher CCD values of the eastern cities highlight the significant differences in new urbanization and sustainable transportation development between the eastern, western, and central cities.

Table 6. Coupling coordination degree (CCD) of nine cities from 2007 to 2016.

\begin{tabular}{cccccccccc}
\hline \multirow{2}{*}{ Year } & \multicolumn{7}{c}{ City } \\
\cline { 2 - 10 } & Beijing & Tianjin & Shanghai & Guangzhou & Chongqing & Chengdu & Wuhan & Zhengzhou & Xi'an \\
\hline 2007 & 0.83 & 0.79 & 0.78 & 0.76 & 0.57 & 0.61 & 0.69 & 0.63 & 0.64 \\
2008 & 0.83 & 0.79 & 0.75 & 0.74 & 0.56 & 0.60 & 0.65 & 0.61 & 0.64 \\
2009 & 0.83 & 0.79 & 0.76 & 0.74 & 0.53 & 0.58 & 0.68 & 0.59 & 0.61 \\
2010 & 0.81 & 0.79 & 0.72 & 0.72 & 0.53 & 0.55 & 0.68 & 0.56 & 0.62 \\
2011 & 0.83 & 0.80 & 0.71 & 0.76 & 0.54 & 0.57 & 0.71 & 0.61 & 0.61 \\
2012 & 0.82 & 0.79 & 0.74 & 0.77 & 0.52 & 0.60 & 0.71 & 0.65 & 0.61 \\
2013 & 0.81 & 0.80 & 0.75 & 0.77 & 0.52 & 0.63 & 0.73 & 0.64 & 0.64 \\
2014 & 0.83 & 0.78 & 0.78 & 0.80 & 0.54 & 0.60 & 0.71 & 0.62 & 0.64 \\
2015 & 0.81 & 0.79 & 0.77 & 0.77 & 0.48 & 0.64 & 0.69 & 0.61 & 0.64 \\
2016 & 0.81 & 0.78 & 0.79 & 0.77 & 0.52 & 0.63 & 0.70 & 0.60 & 0.64 \\
\hline
\end{tabular}

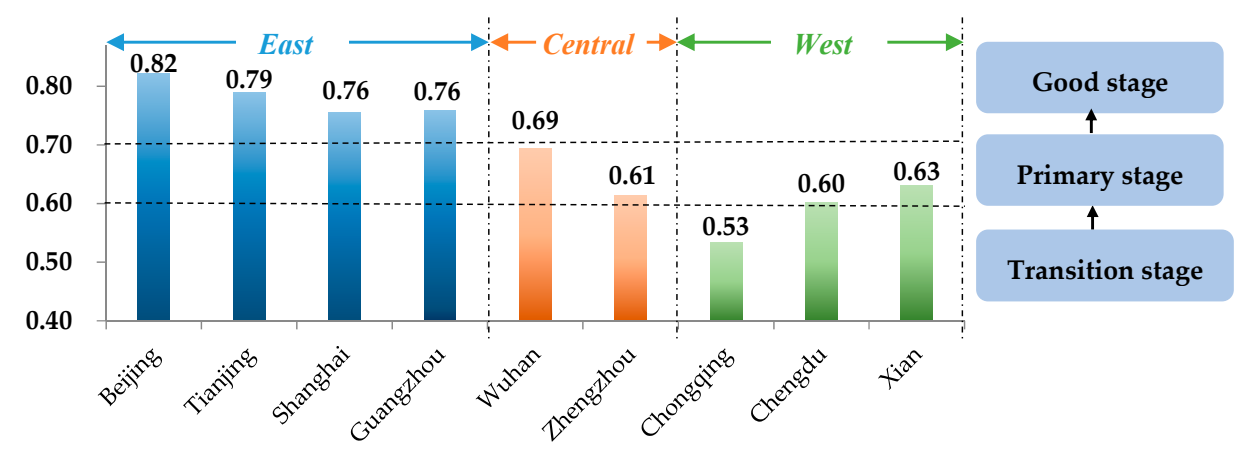

Figure 7. Mean value of CCD in the eastern, central, and western cities. 


\section{3. $G M(1,1)$ Prediction Result Analysis}

Formula (8) was used to calculate the grade ratio of the CCD time series in the eastern, central and western cities, which are shown in Table 7 . The results indicate that the ratios of the three time series fell between 0.83 and 1.20 . As such, the $\mathrm{GM}(1,1)$ model could be used to make predictions.

Table 7. Grade ratio test.

\begin{tabular}{cccc}
\hline Year & Eastern & Central & Western \\
\hline 2008 & 0.9994 & 1.0025 & 0.9773 \\
2009 & 1.0148 & 1.0200 & 1.0163 \\
2010 & 0.9807 & 1.0317 & 1.0049 \\
2011 & 1.0015 & 0.9895 & 0.9705 \\
2012 & 0.9921 & 0.9658 & 0.9972 \\
2013 & 0.9763 & 0.9439 & 0.9819 \\
2014 & 1.0299 & 1.0265 & 1.0121 \\
2015 & 0.9922 & 0.9898 & 1.0503 \\
2016 & 1.0197 & 1.0505 & 1.0107 \\
\hline
\end{tabular}

After the tests above, the time series data were inserted into Formulas (9)-(11), resulting in the following three prediction models for the eastern, western, and central cities, respectively:

$$
\begin{aligned}
& \text { Model one : }{\stackrel{\wedge}{D_{E}}}^{(1)}(k+1)=490.2712 \cdot e^{-0.0016 \cdot k}-489.4855 \\
& \text { Model two : } \stackrel{\wedge}{D}^{(1)}(k+1)=116.3102 \cdot e^{-0.0060 \cdot k}-115.6588 \\
& \text { Model three : }{\stackrel{\wedge}{D_{W}}}^{(1)}(k+1)=381.8880 \cdot e^{-0.0020 \cdot k}-381.2903
\end{aligned}
$$

where $k=1,2,3, \cdots, n$. The cumulative prediction values $\stackrel{\wedge}{(1)}^{(k)}$ of each year were calculated using the models, subtracting the sequence $\stackrel{\wedge}{D}^{(1)}(k)$ to obtain the sequence $\stackrel{\wedge}{D}^{(0)}(k), \stackrel{\wedge}{D}^{(0)}(k)=\stackrel{\wedge}{D}^{(1)}(k)-$ $\stackrel{\wedge}{D}^{(1)}(k-1)$.

The predicted sequences $\hat{D}^{(1)}(k)$ and $\stackrel{\wedge}{D}^{(0)}(k)$ were substituted into Formulas (11) and (12), and the applicability of the model was verified. The results are shown in Table 8.

Table 8. Model test.

\begin{tabular}{ccccccc}
\hline \multirow{2}{*}{ Year } & \multicolumn{2}{c}{ Model One Test } & \multicolumn{2}{c}{ Model Two Test } & \multicolumn{2}{c}{ Model Three Test } \\
\cline { 2 - 6 } & $\begin{array}{c}\text { Residual } \\
\text { Test }\end{array}$ & $\begin{array}{c}\text { Grade Ratio } \\
\text { Deviation Test }\end{array}$ & $\begin{array}{c}\text { Residual } \\
\text { Test }\end{array}$ & $\begin{array}{c}\text { Grade Ratio } \\
\text { Deviation Test }\end{array}$ & $\begin{array}{c}\text { Residual } \\
\text { Test }\end{array}$ & $\begin{array}{c}\text { Grade Ratio } \\
\text { Deviation Test }\end{array}$ \\
\hline 2008 & 0.0074 & 0.0010 & 0.0756 & 0.0086 & 0.3038 & 0.0207 \\
2009 & 0.0204 & 0.0164 & 0.0609 & 0.0262 & 0.2855 & 0.0183 \\
2010 & 0.0005 & 0.0177 & 0.0344 & 0.0380 & 0.2817 & 0.0069 \\
2011 & 0.0006 & 0.0031 & 0.0517 & 0.0045 & 0.3232 & 0.0275 \\
2012 & 0.0102 & 0.0064 & 0.0955 & 0.0283 & 0.3295 & 0.0008 \\
2013 & 0.0363 & 0.0222 & 0.1677 & 0.0504 & 0.3567 & 0.0161 \\
2014 & 0.0078 & 0.0316 & 0.1444 & 0.0327 & 0.3432 & 0.0141 \\
2015 & 0.0174 & 0.0062 & 0.1632 & 0.0042 & 0.2815 & 0.0524 \\
2016 & 0.0007 & 0.0214 & 0.1140 & 0.0568 & 0.2705 & 0.0127 \\
\hline
\end{tabular}

Note: When the residual test and the grade ratio deviation test result are both less than 0.1 , the model has higher feasibility; when the residual test and the grade ratio deviation test result are both less than 0.2 , the model has general applicability. 
Table 8 shows that the grade ratio deviations of Model 1, Model 2, and Model 3 were all less than 0.1. Model 1 and Model 2 residuals were both less than 0.1, making those models more satisfactory. As such, the models could be applied to predict the coordination degree of the three regions. Table 9 and Figure 8 show the prediction results.

Table 9. Coupling coordination degree prediction value.

\begin{tabular}{cccc}
\hline Year & $\begin{array}{c}\text { Forecast Value in } \\
\text { Eastern Cities }\end{array}$ & $\begin{array}{c}\text { Forecast Value in } \\
\text { Central Cities }\end{array}$ & $\begin{array}{c}\text { Forecast Value in } \\
\text { Western Cities }\end{array}$ \\
\hline 2017 & 0.7982 & 0.7687 & 0.7847 \\
2018 & 0.7995 & 0.7734 & 0.7863 \\
2019 & 0.8007 & 0.7780 & 0.7879 \\
2020 & 0.8020 & 0.7828 & 0.7895 \\
2021 & 0.8033 & 0.7875 & 0.7910 \\
2022 & 0.8046 & 0.7922 & 0.7926 \\
2023 & 0.8059 & 0.7970 & 0.7942 \\
2024 & 0.8071 & 0.8018 & 0.7958 \\
2025 & 0.8084 & 0.8067 & 0.7974 \\
\hline
\end{tabular}

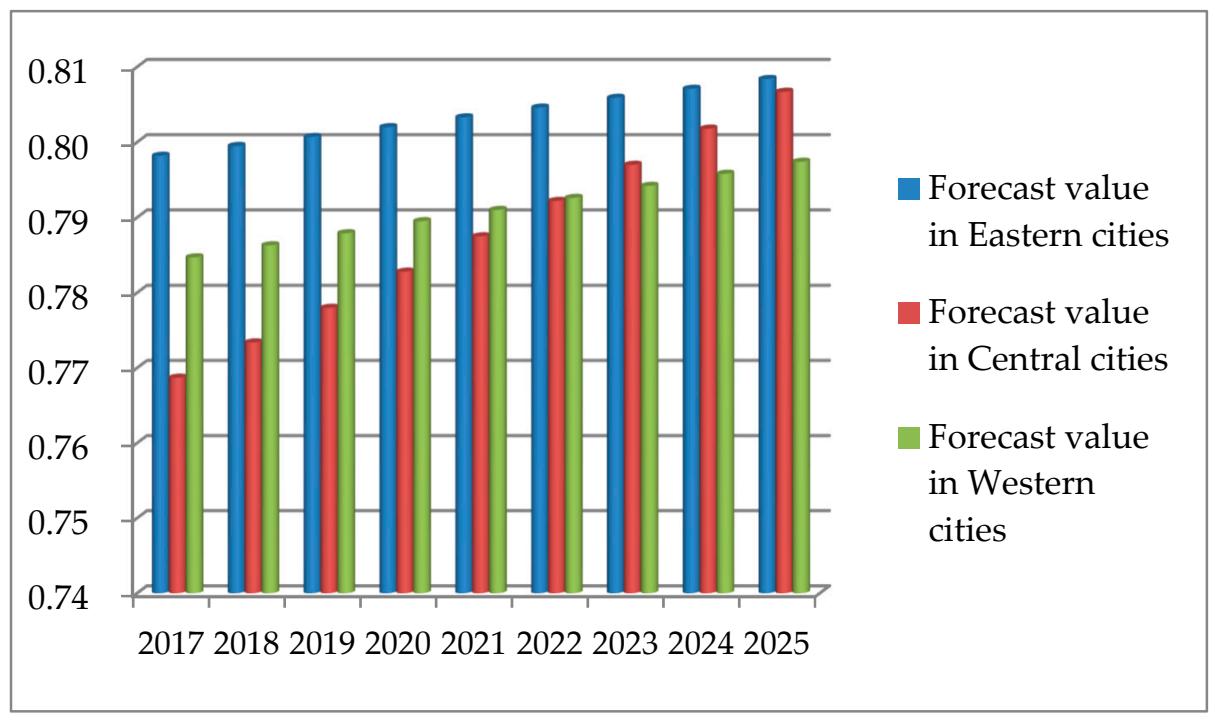

Figure 8. CCD prediction values for the eastern, central, and western Cities.

Figure 8 shows a general annual decrease in the coordination gap between the eastern Cities, the central Cities and the western Cities with respect to NU and ST. In 2025, the coupling coordination degree of each region is predicted to reach $0.79,0.80$; when the two systems will be in the intermediate coordination stage, and regional balanced development will be achieved. This is mainly driven by Beijing, Tianjin, Shanghai, Guangzhou, and the other areas considered to be national first-tier cities, which have the opportunities needed to attract a large number of talented people from across the country.

Although NU has developed rapidly, urban-rural development is not synchronous in China. Some small towns and village governments have insufficient capital investment and weak infrastructure. These result in many migrants moving into larger towns, causing urban housing to become denser and road travel volumes to increase sharply. This creates significant pressure for urban traffic. Urban scale development cannot provide sufficient support for transportation infrastructure, hindering coordinated development between NU and ST.

Zhengzhou and Wuhan are important transportation hubs in China and are industrial and scientific education centers. These cities rely on their own geographical advantages, which play a leading role in the development of the central cities. In the past few years, Zhengzhou and Wuhan 
have accelerated inter-city transportation construction, vigorously developing their advantages in transportation, education, medical care, and other public resources. The rapid development of public transportation, and its national policy support, has also accelerated the speed of new urbanization in the central cities.

The Western Cities have rich historical and cultural resources and relatively low labor costs. In recent years, these cities have been strengthening their economic cooperation, seeking group development opportunities, maximizing their advantages, and increasing the level of new urbanization, all of which cause the western cities to show a more balanced development trend when compared to the eastern and central cities.

\section{Conclusions and Implications}

This study constructed a CCD model to explore the symmetrical coupling between NU and ST. Specifically, it used nine metropolises in China as a case study. The results showed that the CCD values in each city followed different trends. The CCD values of the eastern cities (Beijing, Tianjin, Shanghai, Guangzhou), western cities (Chongqing, Chengdu and Xi'an), and central cities (Zhengzhou and Wuhan) all exhibited growth trends. The western cities had the highest growth rate. Finally, based on the GM $(1,1)$ model, this study predicted that the CCD values of NU and ST in the eastern, central and western cities will be very similar by 2025 , with the eventual achievement of balanced development across all of China's regions. Based on the above findings, this study concludes with the following recommendations.

The current level of new urbanization in central cities and the western cities remains below that of the eastern cities. This is because of the rapid economic development of the eastern cities, the ability to attract talent from different industries, regional advantages, and their strong economic development. For these cities, promoting the urbanization of migrant workers is needed to improve the new urbanization level. These cities can learn from the series of policies and measures promoted by the state to promote population movement to urban areas. This includes giving migrant workers the same rights as urban citizens. Further, promoting regional industrial reform, developing non-agricultural industries, and improving agricultural modernization also require particular focus. In addition, compared with the eastern cities, the central and western cities have a deep cultural background. These local and regional cultures can be integrated to promote new urbanization. For the eastern cities, the level of new urbanization is relatively high, but there remain some problems such as the urban heat island effect, urban traffic congestion and environmental degradation. Therefore, in the development process, there should be a focus on protecting the urban environment and resources, promoting the construction of urban ecological civilizations, increasing the use of environmentally sustainable energy, and enriching urban public transport. Furthermore, appropriate urban land use policies should be formulated to save land and more intensively and efficiently use public resources.

Urban sustainable transportation plays an important role in constructing new urbanization. The degree of responsivity in the traffic network infrastructure determines the travel mode selected by urban residents. The more responsive urban public transportation is, the more likely public transportation will become the main travel mode, and the easier it is to establish an urban sustainable transportation system. The analysis presented here shows that the urban sustainable transportation level remains low in the central and western cities. These areas should take necessary measures to establish a framework for urban sustainable transportation, further enlarge the scale of public transportation, and establish a diversified urban public transportation system. Eco-driving, which can effectively reduce the emission of traffic pollutants without reducing the speed of vehicles should be promoted vigorously. In addition, developing an urban intelligent communication system, and combining advanced science and technology in urban transportation planning could more effectively reduce traffic accidents and improve transportation safety.

The coordinated development of new urbanization and urban sustainable transportation requires considering sustainable transportation while engaging in urban layout design and management. 
The shape, density, and development planning for a city significantly impacts travel behavior and the way people use cars. Compact and corridor-oriented urban development is more likely to achieve sustainable urban transportation. The spatial distribution of urban transportation infrastructure affects how urban residents select their main travel modes. If the work area is not far from the residential area and public transportation is sufficiently convenient, people will prefer to use public transportation or bicycles. This can effectively alleviate urban traffic congestion. At the same time, reducing private cars and developing new energy public transportation will effectively alleviate urban environmental pollution and other problems. These actions can also help achieve new urbanization and sustainable urban development. Therefore, combining a rational urban spatial layout with a more perfect urban public transportation system, and applying information technology in transportation to establish a reasonably intelligent urban transportation system achieves many positive outcomes. The integration can effectively reduce traffic congestion, improve environmental quality, and achieve the goal of sustainable transportation and social sustainability.

This study focused on exploring the coupling coordination relationship between new urbanization and sustainable transportation for nine national metropolises, and predicted the CCD in eastern, central and western cities. We aimed to quantify the relationship between new urbanization and sustainable transportation and provide some policy recommendations for the coordinated development of the two systems. However, with the repaid development of urban economies and social progress, the meaning of new urbanization will evolve to keep pace with the times. This may change the corresponding evaluation indicators. Future research should further study the mechanism between new urbanization and sustainable transportation, identify the factors that hinder their coordinated development, and provide additional theoretical context to support the coordinated development of the two systems.

Author Contributions: For this study, F.M. proposed the idea of this study; F.M. and Y.G. jointly organized the structure of this study; Y.G. established the calculation model; Y.G. and W.S. collected the data and carried out the result calculations; K.Y. and S.W. polished the article.

Funding: This study was financially supported by the National Social Science Foundation of China (grant number 18BGL258).

Conflicts of Interest: The authors declare no conflicts of interest.

\section{References}

1. Li, Y.H.; Wang, X.G.; Sun, X.N. Research on the correlation between typical national urbanization development and transportation and its enlightenment to china. Appl. Mech. Mater. 2015, 744-746, 2120-2125. [CrossRef]

2. Ni, P. The goal, path, and policy responses of China's new urbanization. China Financ. Econ. Rev. 2013, 1, 1-15. [CrossRef]

3. Lane, B.W.; Beeler, J. Sustainable Transport. In International Encyclopedia of Geography: People, the Earth, Environment and Technology; John Wiley \& Sons, Ltd: Hoboken, NJ, USA, 2017; pp. 1-11.

4. Qi, Y. Analysis on Inter-City Bus Sustainable Mode during the Process of New-Type Urbanization Evolution. In Proceedings of the Cota International Conference of Transportation Professionals, Changsha, China, 4-7 July 2014.

5. Banerjee, A.V.; Duflo, E.; Qian, N. On the road: Access to transportation infrastructure and economic growth in china. Soc. Sci. Electron. Publ. 2012, 11, 1-53. [CrossRef]

6. Pauli, G. Sustainable transport: A case study of rhine navigation. Nat. Resour. Forum 2010, 34, $236-254$. [CrossRef]

7. Ji, Y.; Dou, Y. Coordinated Development of New Urbanization and Transport Infrastructure. Acad. Exch. 2016, 127-132. [CrossRef]

8. Saidi, S.; Shahbaz, M.; Akhtar, P. The long-run relationships between transport energy consumption, transport infrastructure, and economic growth in MENA countries. Transp. Res. Pt. A Policy Pract. 2018, 111, 78-95. [CrossRef]

9. Chen, M.; Liu, W.; Lu, D.; Hao, C.; Chao, Y. Progress of China's new-type urbanization construction since 2014: A preliminary assessment. Cities 2018, 78, 180-193. [CrossRef] 
10. China Statistical Yearbook 2017; China Statistics Press: Fengtai District, Beijing, 2018.

11. Chen, M.; Liu, W.; Lu, D. Challenges and the way forward in China's new-type urbanization. Land Use Policy 2016, 55, 334-339. [CrossRef]

12. Chen, T.; Hui, C.M.; Lang, W.; Tao, L. People, recreational facility and physical activity: New-type urbanization planning for the healthy communities in China. Habitat. Int. 2016, 58, 12-22. [CrossRef]

13. Ji, X.; Li, J.; Chen, F. Spatio-temporal Cooperative Evolution Analysis of Transportation Superiority and County Urbanization in Yunnan Province. Sci. Geogr. Sin. 2017, 37, 1875-1884.

14. Gössling, S.; Schröder, M.; Späth, P.; Freytag, T. Urban Space Distribution and Sustainable Transport. Transp. Rev. 2016, 36, 1-21. [CrossRef]

15. Maparu, T.S.; Mazumder, T.N. Transport infrastructure, economic development and urbanization in India (1990-2011): Is there any causal relationship? Transp. Res. Pt. A Policy Pract. 2017, 100, 319-336. [CrossRef]

16. Branea, A.M.; Gaman, M.; Badescu, S. Urban Mobility Analysis on Efficiency and Sustainability by Means of Transportation. In IOP Conference Series: Materials Science and Engineering, Prague, Czech Republic; IOP Publishing: Bristol, UK, 2007; p. 082020.

17. Kwan, S.C.; Sutan, R.; Hashim, J.H. Trip characteristics as the determinants of intention to shift to rail transport among private motor vehicle users in Kuala Lumpur, Malaysia. Sustain. Cities Soc. 2018, 36, 319-326. [CrossRef]

18. Loo, B.P.Y.; Chow, A.S.Y. Changing Urban Form in Hong Kong: What Are the Challenges on Sustainable Transportation? Int. J. Sustain. Transp. 2008, 2, 177-193. [CrossRef]

19. Rukmana, D. Rapid urbanization and the need for sustainable transportation policies in Jakarta. In International Conference on Science, Infrastructure Technology and Regional Development; IOP Publishing Ltd.: Bristol, UK, 2018; p. 124.

20. Ahmad, S.; Oliveira, J.A.P.D. Determinants of urban mobility in India: Lessons for promoting sustainable and inclusive urban transportation in developing countries. Transp. Policy 2016, 50, 106-114. [CrossRef]

21. Guan, D.J.; Gao, W.J.; Su, W.C.; Li, H.F.; Hokao, K. Modeling and dynamic assessment of urban economy-resource-environment system with a coupled system dynamics-geographic information system model. Ecol. Indic. 2011, 11, 1333-1344. [CrossRef]

22. Yu, S.; Yin, C. Analyzing the coupling coordination among economic, social, and environmental benefits of urban infrastructure: Case study of four Chinese autonomous municipalities. Math. Probl. Eng. 2018, 2018, 8280328. [CrossRef]

23. Lei, D.; Weituo, Z.; Yalin, H.; Shenggao, C.; Chao, L. Research on the coupling coordination relationship between urbanization and the air environment: A case study of the area of Wuhan. Atmosphere 2015, 6, 1539-1558. [CrossRef]

24. Wang, S.J.; Ma, H.; Zhao, Y.B. Exploring the relationship between urbanization and the eco-environment-A case study of Beijing-Tianjin-Hebei region. Ecol. Indic. 2014, 45, 171-183. [CrossRef]

25. Castellani, V.; Sala, S. Sustainable performance index for tourism policy development. Tour. Manag. 2010, 31, 871-880. [CrossRef]

26. Hunter, C.; Shaw, J. The ecological footprint as a key indicator of sustainable tourism. Tour. Manag. 2007, 28, 46-57. [CrossRef]

27. Liu, W.; Shi, H.B.; Zhang, Z.; Tsai, S.B.; Zhai, Y.; Chen, Q.; Wang, J. The Development Evaluation of Economic Zones in China. Int. J. Environ. Res. Public Health 2018, 15, 56. [CrossRef] [PubMed]

28. Banister, D. Sustainable urban development and transport-A eurovision for 2020. Transp. Rev. 2000, 20, 113-130. [CrossRef]

29. Pucher, J.; Peng, Z.R.; Mittal, N.; Zhu, Y. Urban transport trends and policies in china and India: Impacts of rapid economic growth. Transp. Rev. 2007, 27, 379-410. [CrossRef]

30. Mu, Y.; Fang, Q. The future of Chinese cities and urban planning with "One Belt, One Road" Strategy. Planners 2016, 32, 5-10. [CrossRef]

31. Xu, C.; Wang, S.; Zhou, Y.; Wang, L.; Liu, W. A Comprehensive Quantitative Evaluation of New Sustainable Urbanization Level in 20 Chinese Urban Agglomerations. Sustainability 2016, 8, 91. [CrossRef]

32. Libang, M.A.; Cheng, W.; Qi, J. Coordinated evaluation and development model of oasis urbanization from the perspective of new urbanization: A case study in Shandan County of Heixi Corridor, China. Sustain. Cities Soc. 2018, 39, 78-92. [CrossRef] 
33. Li, Y.J.; Qi, Y.A.; Zhou, J. The comprehensive appraisement of the new urbanization level based on eight ethnic provinces in China. In Proceedings of the Control and Decision Conference, Chongqing, China, 28-30 May 2017; pp. 3346-3350.

34. Jianwei, H.E.; Zhenxiang, Z.; Zhiheng, L.I. Benefit evaluation framework of intelligent transportation systems. J. Transp. Syst. Eng. Inf. Technol. 2010, 10, 81-87.

35. Liu, S.; Zhang, P.; Wang, Z.; Liu, W.; Tan, J. Measuring the sustainable urbanization potential of cities in Northeast China. J. Geogr. Sci. 2016, 26, 549-567. [CrossRef]

36. Wen, T.; Wang, H.J. Industrial structure, income distribution and China's urbanization. Jilin Univ. J. Soc. Sci. Ed. 2015, 55, 134-143.

37. Xu, W.; Wang, G.Y. The Measure Index System and Evaluation Research of New-Type Urbanization. Appl. Mech. Mater. 2014, 5, 587-589. [CrossRef]

38. Bao, C.; Zou, J. Exploring the Coupling and Decoupling Relationships between Urbanization Quality and Water Resources Constraint Intensity: Spatiotemporal Analysis for Northwest China. Sustainability 2017, 9, 1960. [CrossRef]

39. Yang, S.F.; Hu, S.G.; Ye, J.; Tong, L.Y. Spatial-temporal variation and formation mechanism of neo-urbanization development coordination in central China. Econ. Geogr. 2014, 34, 23-29. [CrossRef]

40. Song, M.; Yin, M.; Chen, X.; Zhang, L.; Li, M. A simulation-based approach for sustainable t ransportation systems evaluation and optimization: Theory, systematic framework and applications. Procedia Soc. Behav. Sci. 2013, 96, 2274-2286. [CrossRef]

41. Zhang, J. Comprehensive Evaluation of Sustainable Development of Urban Transportation System; Southwest Jiao Tong University Press: Chengdu, China, 2014.

42. Kirk, K.; Tableporter, J.; Senn, A.; Day, J.; Cao, J.; Fan, Y.; Slotterback, C.S.; Goetz, E.; McGinnis, L. Framework for Measuring Sustainable Regional Development for the Twin Cities Region, Center for Transportation Studies; University of Minnesota: Minneapolis, MN, USA, 2010.

43. Haghshenas, H.; Vaziri, M. Urban sustainable transportation indicators for global comparison. Ecol. Indic. 2012, 15, 115-121. [CrossRef]

44. Qiu, D.; Pan, A.; Xu, Q.; Xi, Z. Fuzzy comprehensive evaluation of urban transportation sustainable development in Wenzhou city. In Proceedings of the International Conference on Computer Design \& Applications, Qinhuangdao, China, 25-27 June 2010.

45. Rajak, S.; Parthiban, P.; Dhanalakshmi, R. Sustainable transportation systems performance evaluation using fuzzy logic. Ecol. Indic. 2016, 71, 503-513. [CrossRef]

46. Gerike, R.; Koszowski, C. Sustainable Urban Transportation. Encycl. Sustain. Technol. 2017, 6, $379-391$. [CrossRef]

47. Li, Y.; Yang, J.; Shi, H.; Li, Y. Assessment of sustainable urban transport development based on entropy and unascertained measure. PLoS ONE 2017, 12, e0186893. [CrossRef]

48. Zhang, P.; Yang, D.; Erling, L.I.; Yanyan, L.I. The Coupled Coordination Relationship between Land Urbanization and Population Urbanization-A Case Study of the Central Plains Economic Region. Econ. Geogr. 2017. [CrossRef]

49. Dejamkhooy, A.; Dastfan, A.; Ahmadyfard, A. Modeling and Forecasting Non-Stationary Voltage Fluctuation Based on Grey System Theory. IEEE Trans. Power Deliv. 2015, 32, 1212-1219. [CrossRef]

50. Li, C.; Qin, J.; Li, J.; Hou, Q. The accident early warning system for iron and steel enterprises based on combination weighting and Grey Prediction Model GM (1, 1). Saf. Sci. 2016, 89, 19-27. [CrossRef]

51. Bezuglov, A.; Comert, G. Short-term freeway traffic parameter prediction: Application of grey system theory models. Expert Syst. Appl. 2016, 62, 284-292. [CrossRef]

(C) 2019 by the authors. Licensee MDPI, Basel, Switzerland. This article is an open access article distributed under the terms and conditions of the Creative Commons Attribution (CC BY) license (http:/ / creativecommons.org/licenses/by/4.0/). 